\title{
SOME CRITERIA FOR UNIVALENCE OF CERTAIN INTEGRAL OPERATORS
}

\section{VIRGIL PESCAR and SHIGEYOSHI OWA}

Received 21 January 2004 and in revised form 25 March 2004 We derive some criteria for univalence of certain integral operators for analytic functions
in the open unit disk.

2000 Mathematics Subject Classification: 30C45.

1. Introduction. Let $\mathscr{A}$ be the class of the functions $f(z)$ which are analytic in the open unit disk $\mathbb{U}=\{z \in \mathbb{C}:|z|<1\}$ and $f(0)=f^{\prime}(0)-1=0$.

We denote by $\mathscr{S}$ the subclass of $\mathscr{A}$ consisting of functions $f(z) \in \mathscr{A}$ which are univalent in $\mathbb{U}$. Miller and Mocanu [1] have considered many integral operators for functions $f(z)$ belonging to the class $\mathscr{A}$. In this paper, we consider the integral operators

$$
F_{\alpha}(z)=\left\{\frac{1}{\alpha} \int_{0}^{z}(f(u))^{1 / \alpha} u^{-1} d u\right\}^{\alpha} \quad(z \in \mathbb{U})
$$

for $f(z) \in \mathscr{A}$ and for some $\alpha \in \mathbb{C}$. It is well known that $F_{\alpha}(z) \in \mathscr{Y}$ for $f(z) \in \mathscr{S}^{*}$ and $\alpha>0$, where $\mathscr{S}^{*}$ denotes the subclass of $\mathscr{S}$ consisting of all starlike functions $f(z)$ in $\mathbb{U}$.

2. Preliminary results. To discuss our integral operators, we need the following theorems.

THEOREM 2.1 [3]. Let $\alpha$ be a complex number with $\operatorname{Re}(\alpha)>0$ and $f(z) \in \mathscr{A}$. If $f(z)$ satisfies

$$
\frac{1-|z|^{2 \operatorname{Re}(\alpha)}}{\operatorname{Re}(\alpha)}\left|\frac{z f^{\prime \prime}(z)}{f^{\prime}(z)}\right| \leqq 1,
$$

for all $z \in \mathbb{U}$, then the integral operator

$$
G_{\alpha}(z)=\left\{\alpha \int_{0}^{z} u^{\alpha-1} f^{\prime}(u) d u\right\}^{1 / \alpha}
$$

is in the class $\mathscr{Y}$. 
THEOREM 2.2 [4]. Let $\alpha$ be a complex number with $\operatorname{Re}(\alpha)>0$ and $f(z) \in A$. If $f(z)$ satisfies (2.1) for all $z \in \mathbb{U}$, then, for any complex number $\beta$ with $\operatorname{Re}(\beta) \geqq \operatorname{Re}(\alpha)$, the integral operator

$$
G_{\beta}(z)=\left\{\beta \int_{0}^{z} u^{\beta-1} f^{\prime}(u) d u\right\}^{1 / \beta}
$$

is in the class $\mathscr{Y}$.

EXAMPLE 2.3. Defining the function $f(z)$ by

$$
f(z)=\int_{0}^{z}\left(\frac{1+u^{\operatorname{Re}(\alpha)}}{1-u^{\operatorname{Re}(\alpha)}}\right)^{1 / 2} d u
$$

with $\operatorname{Re}(\alpha)>0$, we have that

$$
\frac{1-z^{2 \operatorname{Re}(\alpha)}}{\operatorname{Re}(\alpha)}\left(\frac{z f^{\prime \prime}(z)}{f^{\prime}(z)}\right)=z^{\operatorname{Re}(\alpha)} .
$$

Thus the function $f(z)$ satisfies the condition of Theorem 2.2. Therefore, for $\operatorname{Re}(\beta) \geqq$ $\operatorname{Re}(\alpha)$,

$$
G_{\beta}(z)=\left\{\beta \int_{0}^{z} u^{\beta-1}\left(\frac{1+u^{\operatorname{Re}(\alpha)}}{1-u^{\operatorname{Re}(\alpha)}}\right)^{1 / 2} d u\right\}^{1 / \beta}
$$

is in the class $\mathscr{Y}$.

THEOREM 2.4 [2]. If the function $g(z)$ is regular in $\mathbb{U}$, then, for all $\xi \in \mathbb{U}$ and $z \in \mathbb{U}$, $g(z)$ satisfies

$$
\begin{gathered}
\left|\frac{g(\xi)-g(z)}{1-\overline{g(z)} g(\xi)}\right| \leqq\left|\frac{\xi-z}{1-\bar{z} \xi}\right|, \\
\left|g^{\prime}(z)\right| \leqq \frac{1-|g(z)|^{2}}{1-|z|^{2}} .
\end{gathered}
$$

The equalities hold only in the case $g(z)=\varepsilon((z+u) /(1+\bar{u} z))$, where $|\varepsilon|=1$ and $|u|<1$.

REMARK 2.5 [2]. For $z=0$, from inequality (2.7),

$$
\left|\frac{g(\xi)-g(0)}{1-\overline{g(0)} g(\xi)}\right| \leqq|\xi|
$$

and, hence

$$
|g(\xi)| \leqq \frac{|\xi|+|g(0)|}{1+|g(0)||\xi|}
$$

Considering $g(0)=a$ and $\xi=z$, we see that

$$
|g(z)| \leqq \frac{|z|+|a|}{1+|a||z|}
$$

for all $z \in \mathbb{U}$. 
SCHWARZ LEMMA [2]. If the function $g(z)$ is regular in $\mathbb{U}, g(0)=0$, and $|g(z)| \leqq 1$, for all $z \in \mathbb{U}$, then

$$
|g(z)| \leqq|z|
$$

for all $z \in \mathbb{U}$, and $\left|g^{\prime}(0)\right| \leqq 1$. The equality in (2.12) for $z \neq 0$ holds only in the case $g(z)=\epsilon z$, where $|\epsilon|=1$.

\section{Main results}

THEOREM 3.1. Let $\alpha$ be a complex number with $\operatorname{Re}(1 / \alpha)=a>0$ and the function $g(z) \in A$ satisfying

$$
\left|\frac{z g^{\prime}(z)}{g(z)}-1\right| \leqq 1 \quad(z \in \mathbb{U})
$$

Then, for

$$
|\alpha| \geqq \frac{2}{(2 a+1)^{(2 a+1) / 2 a}},
$$

the integral operator

$$
F_{\alpha}(z)=\left\{\frac{1}{\alpha} \int_{0}^{z}(g(u))^{1 / \alpha} u^{-1} d u\right\}^{\alpha}
$$

is in the class $\mathscr{Y}$.

Proof. Let $1 / \alpha=\beta$. Then we have

$$
F_{1 / \beta}(z)=\left\{\beta \int_{0}^{z} u^{\beta-1}\left(\frac{g(u)}{u}\right)^{\beta} d u\right\}^{1 / \beta} .
$$

We consider the function

$$
f(z)=\int_{0}^{z}\left(\frac{g(u)}{u}\right)^{\beta} d u
$$

Then the function

$$
h(z)=\left(\frac{1}{|\beta|}\right) \frac{z f^{\prime \prime}(z)}{f^{\prime}(z)}
$$

is regular in $\mathbb{U}$ and the constant $|\beta|$ satisfies the inequality

$$
|\beta| \leqq \frac{(2 a+1)}{2}^{(2 a+1) / 2 a} .
$$

From (3.5) and (3.6), we have that

$$
h(z)=\frac{\beta}{|\beta|}\left(\frac{z g^{\prime}(z)}{g(z)}-1\right) .
$$


Using (3.8) and (3.1), we obtain

$$
|h(z)| \leqq 1 \quad(z \in \mathbb{U}) .
$$

Noting that $h(0)=0$ and applying the Schwarz lemma for $h(z)$, we get

$$
\frac{1}{|\beta|}\left|\frac{z f^{\prime \prime}(z)}{f^{\prime}(z)}\right| \leqq|z| \quad(z \in \mathbb{U})
$$

and hence we obtain

$$
\frac{1-|z|^{2 a}}{a}\left|\frac{z f^{\prime \prime}(z)}{f^{\prime}(z)}\right| \leqq|\beta|\left(\frac{1-|z|^{2 a}}{a}\right)|z| \quad(z \in \mathbb{U}) .
$$

Because

$$
\max _{|z| \leq 1}\left(\frac{1-|z|^{2 a}}{a}|z|\right)=\frac{2}{(2 a+1)^{(2 a+1) / 2 a}}
$$

from (3.11) and (3.7), we have

$$
\frac{1-|z|^{2 a}}{a}\left|\frac{z f^{\prime \prime}(z)}{f^{\prime}(z)}\right| \leqq 1
$$

for $z \in \mathbb{U}$. From (3.13) and Theorem 2.1, it follows that (2.4) belongs to the class $\mathscr{Y}$.

By means of (2.4) and (3.5), we have that the integral operator $F_{1 / \beta}(z)$ is in the class $\mathscr{Y}$, and hence we conclude that the integral operator $F_{\alpha}(z)$ is in the class $\mathscr{Y}$.

EXAMPLE 3.2. If we take the function $g(z)=z e^{z}$ and $\alpha=1 / a>0$, then

$$
g(z)=z+a_{2} z^{2}+a_{3} z^{3}+\cdots
$$

is analytic in $\mathbb{U}$ and

$$
\left|\frac{z g^{\prime}(z)}{g(z)}-1\right|=|z|<1 \quad(z \in \mathbb{U})
$$

Since the function $g(z)$ satisfies the condition of Theorem 3.1, we have

$$
T_{\alpha}(z)=\left\{\frac{1}{\alpha} \int_{0}^{z} e^{u / \alpha} u^{1 / \alpha-1} d u\right\}^{\alpha} \in \mathscr{S}
$$

THeOREM 3.3. Let $\alpha, \beta$ be complex numbers with $\operatorname{Re}(\beta) \geqq \operatorname{Re}(\alpha)>0$ and the function $g(z) \in \mathscr{A}$ satisfying

$$
\left|\frac{z g^{\prime}(z)-g(z)}{z g(z)}\right| \leqq 1 \quad(z \in \mathbb{U})
$$

Then, for

$$
|\alpha| \geqq \max _{|z| \leqq 1}\left\{\left(\frac{1-|z|^{2 \operatorname{Re}(\alpha)}}{\operatorname{Re}(\alpha)}\right)|z|\left(\frac{|z|+\left|a_{2}\right|}{1+\left|a_{2}\right||z|}\right)\right\},
$$


the integral operator

$$
F_{\alpha, \beta}(z)=\left\{\beta \int_{0}^{z}(g(u))^{1 / \alpha} u^{\beta-1 / \alpha-1} d u\right\}^{1 / \beta}
$$

is in the class $\mathscr{Y}$.

Proof. We have

$$
F_{\alpha, \beta}(z)=\left\{\beta \int_{0}^{z} u^{\beta-1}\left(\frac{g(u)}{u}\right)^{1 / \alpha} d u\right\}^{1 / \beta}
$$

We consider the function

$$
f(z)=\int_{0}^{z}\left(\frac{g(u)}{u}\right)^{1 / \alpha} d u
$$

which is regular in $\mathbb{U}$. The function

$$
p(z)=|\alpha| \frac{f^{\prime \prime}(z)}{f^{\prime}(z)}
$$

where the constant $|\alpha|$ satisfies inequality (3.18), is regular in $\mathbb{U}$. From (3.22) and (3.21), we obtain

$$
p(z)=\frac{|\alpha|}{\alpha}\left\{\frac{z g^{\prime}(z)-g(z)}{z g(z)}\right\}
$$

and using (3.17), we have

$$
|p(z)|<1 \quad(z \in \mathbb{U})
$$

and $|p(0)|=\left|a_{2}\right|$. Applying Remark 2.5, we obtain

$$
\left|\alpha \frac{f^{\prime \prime}(z)}{f^{\prime}(z)}\right| \leq \frac{|z|+\left|a_{2}\right|}{1+\left|a_{2}\right||z|} \quad(z \in \mathbb{U}) .
$$

It follows that

$$
\frac{1-|z|^{2 \operatorname{Re}(\alpha)}}{\operatorname{Re}(\alpha)}\left|\frac{z f^{\prime \prime}(z)}{f^{\prime}(z)}\right| \leqq\left(\frac{1}{|\alpha|}\right)\left(\frac{1-|z|^{2 \operatorname{Re}(\alpha)}}{\operatorname{Re}(\alpha)}\right)|z|\left(\frac{|z|+\left|a_{2}\right|}{1+\left|a_{2}\right||z|}\right)
$$

for all $z \in \mathbb{U}$. We consider the function

$$
Q(x)=\left(\frac{1-x^{2 \operatorname{Re}(\alpha)}}{\operatorname{Re}(\alpha)}\right) x\left(\frac{x+\left|a_{2}\right|}{1+\left|a_{2}\right| x}\right) \quad(x=|z| ; x \in[0,1]) .
$$

Because $Q(1 / 2)>0, Q(x)$ satisfies

$$
\max _{x \in[0,1]} Q(x)>0
$$


Using this fact, (3.26) gives us that

$$
\frac{1-|z|^{2 \operatorname{Re}(\alpha)}}{\operatorname{Re}(\alpha)}\left|z \frac{f^{\prime \prime}(z)}{f^{\prime}(z)}\right| \leqq \frac{1}{|\alpha|} \max _{|z| \leqq 1}\left\{\left(\frac{1-|z|^{2 \operatorname{Re}(\alpha)}}{\operatorname{Re}(\alpha)}\right)|z|\left(\frac{|z|+\left|a_{2}\right|}{1+\left|a_{2}\right||z|}\right)\right\} .
$$

From (3.29) and (3.18), we obtain (2.1). Using (2.1) and Theorem 2.2, we obtain that the integral operator (2.4) belongs to the class $\mathscr{Y}$. Therefore, it follows from (2.4) and (3.21) that $F_{\alpha, \beta}(z)$ is in the class $\mathscr{Y}$.

COROLlaRY 3.4. Let $\alpha$ be a complex number with $\operatorname{Re}(\alpha)>0$ and the function $g(z) \in$ A satisfying (3.18). Then, for

$$
\max _{|z| \leqq 1}\left\{\left(\frac{1-|z|^{2 \operatorname{Re}(\alpha)}}{\operatorname{Re}(\alpha)}\right)|z|\left(\frac{|z|+\left|a_{2}\right|}{1+\left|a_{2}\right||z|}\right)\right\} \leqq|\alpha| \leqq 1,
$$

the integral operator (3.3) is in the class $\mathscr{Y}$.

Proof. From Theorem 3.3 for $\beta=1 / \alpha$, the condition $\operatorname{Re}(\beta) \geqq \operatorname{Re}(\alpha)>0$ is identical with $|\alpha|<1$ and we have $F_{\alpha, \beta}(z)=F_{\alpha}(z)$.

ACKNOWLEDGMENT. The authors thankfully acknowledge the kind and helpful advice of Professor H. M. Srivastava on the paper.

\section{REFERENCES}

[1] S. S. Miller and P. T. Mocanu, Differential Subordinations. Theory and applications, Monographs and Textbooks in Pure and Applied Mathematics, vol. 225, Marcel Dekker, New York, 2000.

[2] Z. Nehari, Conformal Mapping, McGraw-Hill, New York, 1952.

[3] N. N. Pascu, On a univalence criterion. II, Itinerant Seminar on Functional Equations, Approximation and Convexity (Cluj-Napoca, 1985), Preprint, vol. 85, Universitatea "BabeşBolyai", Cluj-Napoca, 1985, pp. 153-154.

[4] _ An improvement of Becker's univalence criterion, Proceedings of the Commemorative Session: Simion Stoïlow (Braşov, 1987), University of Braşov, Braşov, 1987, pp. 4348.

Virgil Pescar: Department of Mathematics, Faculty of Mathematics and Computer Science, Transilvania University of Braşov, 2200 Braşov, Romania

E-mail address: virgi 1pescar@hotmai1.com

Shigeyoshi Owa: Department of Mathematics, Kinki University, Higashi-Osaka, Osaka 5778502, Japan

E-mail address: owa@math.kindai .ac.jp 


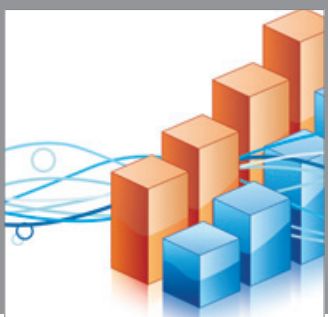

Advances in

Operations Research

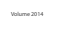

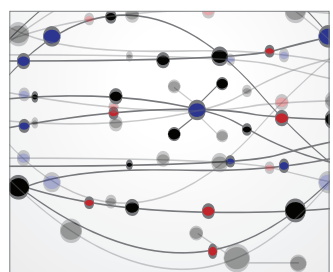

\section{The Scientific} World Journal
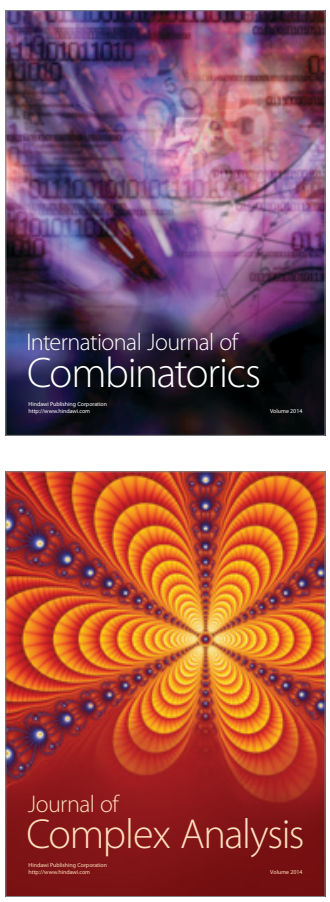

International Journal of

Mathematics and

Mathematical

Sciences
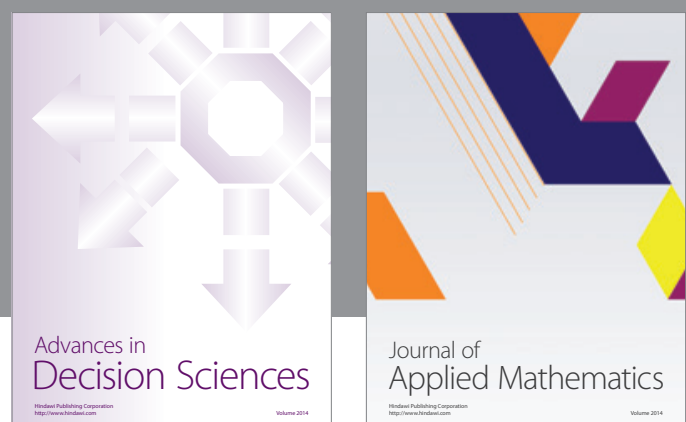

Journal of

Applied Mathematics
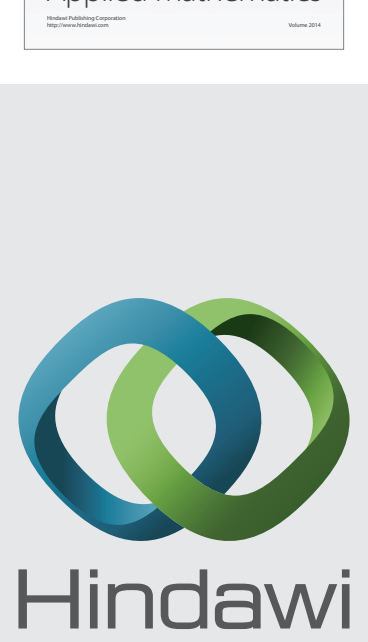

Submit your manuscripts at http://www.hindawi.com
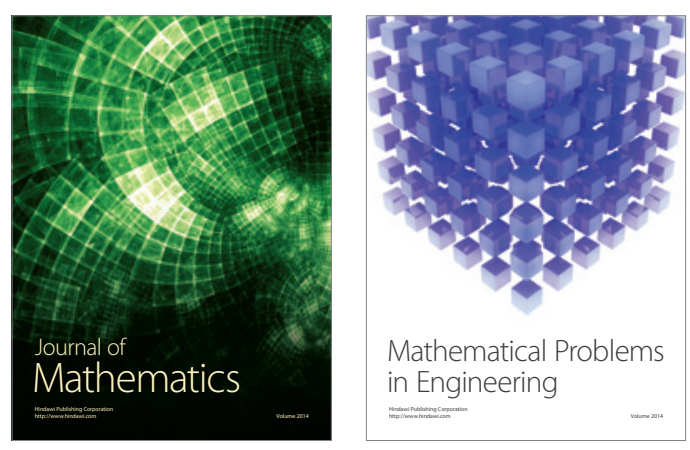

Mathematical Problems in Engineering
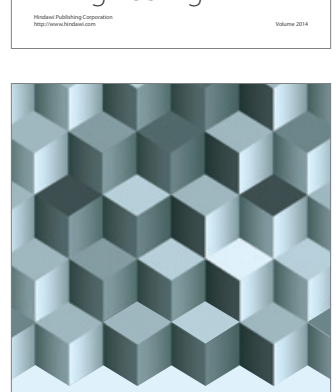

Journal of

Function Spaces




ournal of

Probability and Statistics

Promensencen
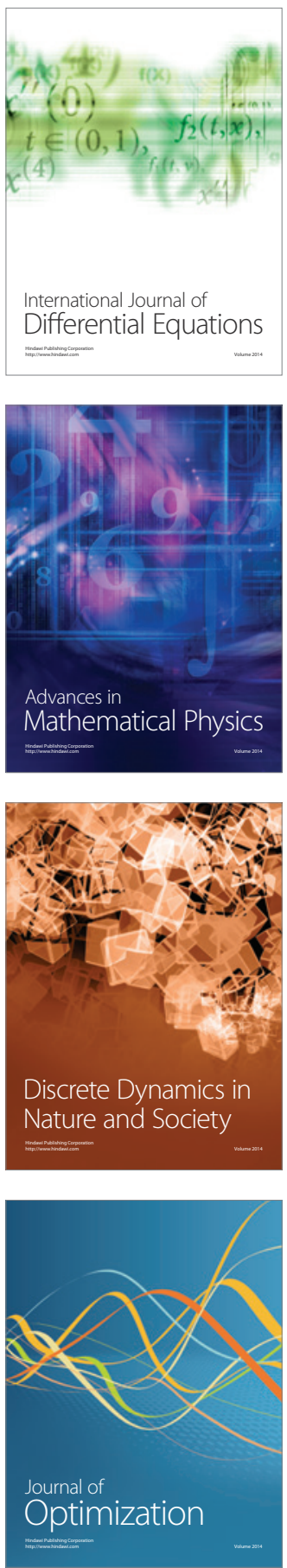